\title{
A protocol for coordinating post-tsunami field reconnaissance efforts in the USA
}

\author{
Rick Wilson • Nathan Wood • Laura Kong • Mike Shulters • \\ Kevin Richards • Paula Dunbar • Gen Tamura $\cdot$ Ed Young
}

Received: 29 January 2014/Accepted: 3 September 2014/Published online: 12 September 2014

(C) The Author(s) 2014. This article is published with open access at Springerlink.com

\begin{abstract}
In the aftermath of a catastrophic tsunami, much is to be learned about tsunami generation and propagation, landscape and ecological changes, and the response and recovery of those affected by the disaster. Knowledge of the impacted area directly helps response and relief personnel in their efforts to reach and care for survivors and for reestablishing community services. First-hand accounts of tsunami-related impacts and consequences also help researchers, practitioners, and policy makers in other parts of the
\end{abstract}

R. Wilson

California Geological Survey, 801 K Street, MS 12-31, Sacramento, CA 95814, USA

N. Wood $(\bowtie)$

Western Geographic Science Center, U.S. Geological Survey, 2130 SW 5th Avenue, Portland, OR 97201, USA

e-mail: nwood@usgs.gov

L. Kong

International Tsunami Information Center, U.S. National Oceanic and Atmospheric Administration, 1845 Wasp Blvd., Bldg. 176, Honolulu, HI 96818, USA

M. Shulters

U.S. Geological Survey, 3020 State University Drive East, Sacramento, CA 95819, USA

K. Richards

Hawaii State Civil Defense, 3949 Diamond Head Road, Honolulu, HI 96816, USA

P. Dunbar

National Geophysical Data Center, U.S. National Oceanic and Atmospheric Administration, 325 South Broadway St., Boulder, CO 80305, USA

G. Tamura

Region IX, U.S. Federal Emergency Management Agency, 546 Bonney Loop Building 520,

Fort Shafter, HI 96858, USA

E. Young

Pacific Region, National Weather Service, U.S. National Oceanic and Atmospheric Administration, 2525 Correa Rd, Ste 250, Honolulu, HI 96822, USA 
world that lack recent events to better understand and manage their own societal risks posed by tsunami threats. Conducting post-tsunami surveys and disseminating useful results to decision makers in an effective, efficient, and timely manner is difficult given the logistical issues and competing demands in a post-disaster environment. To facilitate better coordination of field-data collection and dissemination of results, a protocol for coordinating post-tsunami science surveys was developed by a multi-disciplinary group of representatives from state and federal agencies in the USA. This protocol is being incorporated into local, state, and federal post-tsunami response planning through the efforts of the Pacific Risk Management 'Ohana, the U.S. National Tsunami Hazard Mitigation Program, and the U.S. National Plan for Disaster Impact Assessments. Although the protocol was designed to support a coordinated US post-tsunami response, we believe it could help inform post-disaster science surveys conducted elsewhere and further the discussion on how hazard researchers can most effectively operate in disaster environments.

Keywords Tsunami $\cdot$ Disaster $\cdot$ Fieldwork $\cdot$ Survey $\cdot$ Protocols

\section{Introduction}

On September 29, 2009, an $\mathrm{M}_{\mathrm{w}} 8.0$ earthquake in the Samoa Islands region of the South Pacific Ocean generated a series of tsunami waves that caused substantial damage and loss of life in Samoa, American Samoa, and Tonga. The tsunami killed 192 people and caused approximately $\$ 275$ million (USD) in damages to these coastal communities (National Geophysical Data Center/World Data Service for Geophysics 2013). Because of the remoteness of the event, immediate disaster response and relief efforts to help survivors and recovery efforts to re-establish community services were challenging and stressful to public officials.

In addition to emergency and relief personnel, tsunami researchers came to the region to document as much as they could about the 2009 Samoa Islands region tsunami and its impacts before the loss of ephemeral data, such as high-water marks, deposited sediment, and structural and infrastructure damage. When shared properly and in a timely manner to first responders and other personnel, this early damage assessment information can guide response and relief efforts, such as knowing impacted areas that may be difficult to enter because of substantial debris and sediment deposition.

For researchers and public officials in the USA, the 2009 event provided insight into how modern US coastal communities (in this case the Territory of American Samoa) are affected by near-field tsunamis. The last large near-field tsunami with similar effects to strike US coastal communities was the devastating $1964 \mathrm{M}_{\mathrm{w}} 9.2$ Great Alaska Earthquake and Tsunami in the eastern Aleutian-Alaska Subduction Zone (AASZ) (National Geophysical Data Center/World Data Service for Geophysics 2013). Therefore, much could be learned from the 2009 event to assist other emergency managers in their efforts to understand, respond to, and mitigate societal risks associated with other near-field tsunami threats in the USA, such as the AASZ, the Cascadia Subduction Zone in the U.S. Pacific Northwest, the Puerto Rico Trench in the Caribbean Sea, Hawaii, and the Mariana Trench in the western Pacific Ocean.

Those working in American Samoa in the aftermath of the 2009 event found posttsunami efforts to be stressful and chaotic not only because of the remoteness and isolation 
of the islands and its limited post-tsunami lodging, transportation, and communication infrastructure, but also because of the lack of sufficient pre-planning, on-site coordination, information sharing, and communication between emergency-response officials responding to the disaster and researchers collecting impact data on it (John Goeke, American Samoa Department of Homeland Security, oral communication, March 15, 2011). This has been a common challenge after every major tsunami throughout the world and is especially stressful for smaller communities that do not have the resources for coordinating response and recovery activities in extreme events United Nations Educational, Scientific and Cultural Organization's (UNESCO 2014). According to the International Tsunami Information Center (ITIC), which has facilitated and coordinated international post-tsunami science surveys over the past decades, more than 40 scientists and seven teams conducted surveys in American Samoa of variable lengths of time starting just 5 days after the event (Kong et al. 2009).

As a direct response to the aftermath in American Samoa from the 2009 tsunami, a posttsunami science-survey (PTSS) working group was formed at the 2011 annual meeting held in American Samoa of the Pacific Risk Management 'Ohana (PRiMO), which is a consortium of US local, national, and regional agencies, institutions, and organizations committed to enhancing the disaster resilience of the Pacific Islands (PRiMO 2011). Concurrently, a post-event science-survey plan was recommended at the 2011 annual meeting of the U.S. National Tsunami Hazard Mitigation Program (NTHMP), which is a program led by the U.S. National Oceanic and Atmospheric Administration (NOAA) and includes representation from NOAA, the U.S. Geological Survey (USGS), the U.S. Federal Emergency Management Agency (FEMA), and each open-ocean, coastal state, territory, and commonwealth (National Tsunami Hazard Mitigation Program 2011). These efforts combined into a single PTSS working group that included representatives from federal (NOAA, FEMA, and USGS) and state response and science agencies (Hawaii State Civil Defense and California Geological Survey). The group presented its draft protocol in December 2011 at the Fall American Geophysical Union meeting (Kong et al. 2011).

The concept of formal, systematic, and coordinated PTSS teams is not new and started in the 1990s when international tsunami survey teams began to collect run-up and inundation data after destructive tsunamis around the world for use in validating and benchmarking numerical models. The September 2, 1992, Nicaragua tsunami was the first event to have formally designated tsunami survey teams (Satake et al. 1993; Piatanesi et al. 1996; Synolakis and Okal 2005) and subsequent tsunamis throughout the world after 1992 resulted in additional survey teams (e.g., Sato et al. 1995; Synolakis et al. 1995; Borrero et al. 1997). The proliferation of survey teams led to the development of a post-tsunami field-survey guide first published in 1998 by the United Nations Educational, Scientific and Cultural Organization's Intergovernmental Oceanographic Commission (UNESCO-IOC) to provide the scientific community with international guidance on collecting perishable tsunami data immediately after the event (UNESCO 2014). The scale and magnitude of the December 2004 Indian Ocean disaster led to an unprecedented number of tsunami research investigations, as well as an expansion of the type of collected data. As a result, a second edition was published in 2014 to update International Tsunami Survey Teams (ITST) survey guidance, field techniques, and post-tsunami data archiving (Kong 2011; UNESCO 2014). The post-tsunami protocol summarized in this article builds on the UNESCO field guide but focuses on efforts to improve coordination and communication for surveys conducted in the USA and its federal, state, and local emergency-response framework. The protocol serves the needs of scientists, while also respecting the roles of government emergency managers, disaster personnel, local experts, and affected populations. 
The objective of this paper is to illustrate the components of a protocol for coordinating PTSS in the USA. The protocol consists of ten components recommended to be followed by tsunami researchers and impacted states, territories, and commonwealths immediately following a tsunami and focuses on the logistical issues of communication, coordination, and collaboration. We believe that this protocol could benefit physical scientists and engineers, social scientists, affected communities, local, state, and federal officials and emergency responders. A primary goal of the protocol is to help government officials in the USA facilitate the immediate gathering of essential ephemeral data while not compromising the response, relief, and recovery efforts. If properly followed by tsunami researchers and on-site emergency officials, this protocol would yield more-efficient logistics in field-data collection, better data that leverage relationships between researchers, public officials, and local experts, improved communication between researcher and decision makers, and accountability of all participants. The authors of this paper, who not only represent state and federal agencies but also organizations like the NTHMP, ITIC, and PRiMO have post-event experiences and have initiated work to include the protocol into their response procedures.

\section{Ethical considerations with post-tsunami field surveys}

Before discussing specific components of the protocol, it is important to first acknowledge the ethical considerations of operating in a post-disaster environment and interacting with local populations. Regardless if survey teams are mapping post-tsunami sedimentation or evaluating disaster response efforts, they will be interacting to varying degrees with individuals directly or indirectly affected by the disaster. Engagement could include interviewing survivors, collaborating with local experts, and briefing local officials on survey plans and results.

Survey teams in the USA that are explicitly conducting research involving human subjects, such as interviewing survivors about their evacuation behavior or shelter conditions, will need to adhere to existing policies and regulations contained in the Federal Policy for the Protection of Human Subjects, also referred to as the "Common Rule." This uniform set of rules on existing human subject regulations was initiated by the U.S. Department of Health and Human Services in the 1974 National Research Act (Public Law 93-348, Title 45 Code of Federal Regulations, Part 46) and later codified in separate regulations in 1991 by 15 agencies, including the National Science Foundation, the Department of Defense, and the Agency for International Development. The U.S. Department of Homeland Security, the agency that oversees FEMA, has not issued its own regulations but does comply with Common Rule language (U.S. Department of Health and Human Services 2014). The Common Rule applies to all research involving human subjects in the USA and outlines review procedures for receiving project approval through institutional review boards that are set up within departments, agencies, academic institutions, or other organizations.

Surveys that do not involve human subjects may not require official certification from an institutional review board but should still be sensitive to the fact that they are working in disaster zones in any interactions with local populations. The Belmont Report, first published in 1978 and the basis for later regulations governing the protection of human subjects, outlines three fundamental ethical principles that are applicable to survey teams-respect for persons, beneficence, and justice (U.S. Department of Health and Human Services 1979). Respect for persons includes respecting the autonomy of all 
people, protecting individuals with diminished autonomy, and being truthful, open, and courteous. Beneficence involves doing no harm, maximizing benefits, and minimizing risks to human subjects. Justice ensures that efforts are reasonable, non-exploitative, and administered fairly. Adherence to these principles by all field-survey teams, regardless if they are social scientists, natural scientists, or engineers, will enable researchers to collect useful data without causing additional undue harm to survivors or affected officials.

\section{Protocol components}

Effective, efficient, and timely PTSSs require the coordination and collaboration of multiple people from different disciplines and agencies working in a disaster zone. Situational awareness will vary among all those that are involved and each will have their own goals and criteria for success while in the field. We contend that the ultimate goal is for researchers to gather ephemeral data that may be of immediate use to response personnel, as well as inform others in their efforts to better understand, prepare for, and mitigate future tsunamis elsewhere in the world. The following sections describe each component in the protocol for post-tsunami research from the perspective of tsunami researchers and are organized in chronological order, including pre-field planning, field procedures, and exit strategies (Fig. 1). Protocols of tsunami field teams should be integrated with field teams and information clearinghouses for other hazards, especially earthquake protocol plans since earthquakes and tsunami field specialists may be working together.

\subsection{Pre-field planning}

\subsubsection{Contact event coordinator for situational awareness}

Prior to entering a disaster area to conduct a field survey, tsunami researchers should first contact a designated state/territorial/commonwealth event coordinator to discuss conditions of the impacted area, plans of other survey teams, and any needs for local logistical support. Event coordinators will follow their existing tsunami response plan, which will be aligned with their state's Standardized Emergency Management System (SEMS) and the National Incident Management System (NIMS) at the federal level. Ideally, event coordinators will have already met with local officials to determine their needs and concerns. This discussion will minimize the potential for redundant data-collection efforts, for scientists putting themselves unnecessarily in harm's way, and for ensuring that the useful data can assist in response and recovery operations. A post-tsunami event coordinator to

\section{Protocol components to guide post-tsunami science surveys \\ Pre-field planning \\ 1) Contact event coordinator \\ 2) Prepare and share field plan \\ 3) Obtain official survey badge \\ 4) Include local experts on your team \\ 5) Coordinate and communicate with others \\ Field procedures \\ 6) Follow check in procedures \\ 7) Heed all safety regulations \\ 8) Be prepared to answer questions \\ of response personnel, officials, \\ and survivors \\ Exiting the field \\ 9) Follow check-out procedures and provide out-briefings \\ 10) Provide final data to the appropriate users in a timely fashion}

Fig. 1 Schematic of the primary components in a US protocol for post-tsunami science surveys. Additional details on similar elements from an international and field-researcher perspective are noted in UNESCO (2014) 
serve as the point-of-contact for scientific activities can be identified for tsunami-prone regions in the USA through the NTHMP. In most cases, this event coordinator is a local expert at the state level and/or resident in the region or State, and has been involved in establishing standard-operating procedures (SOP) to be implemented with local team leads. Examples include tsunami program managers at state emergency-management departments, state geological surveys, tsunami information centers, universities, or regional tsunami work groups or organizations. The NTHMP also serves in an advisory capacity for the purpose of identifying additional qualified candidates to serve as coordinator (National Tsunami Hazard Mitigation Program 2011).

Because the post-disaster timeline is highly compressed and event coordinators will have multiple responsibilities immediately after an extreme event, tsunami researchers could make efforts now to establish relationships with state tsunami program managers. This minimizes the potential for having to establish these relationships in the aftermath of a tsunami. The relationships can be built through the various tsunami working or advisory groups that exist in several states, such as the California Tsunami Steering Committee or the regional Redwood Coast Tsunami Work Group in northern California (Dengler et al. 2008), and the ITIC in Hawaii, as well as through NTHMP meetings.

\subsubsection{Prepare and share field plan with event coordinator}

After learning about current conditions in the impacted areas, researchers, or survey teams, interested in conducting PTSSs should provide a field plan to the designated event coordinator that includes field-survey team members, and describes in general terms where they will be and what data they plan to collect. A field plan should also include information on how data-collection progress and preliminary findings will or could be shared with other survey teams, government officials, and relief agencies while researchers are in the field. Each individual working in the impacted zone may have preferred mechanisms for sending or receiving preliminary findings; therefore, researchers should be open to various communication channels and options. Including these communication strategies up front in the field plan makes the process more transparent and reduces the potential for unmet expectations and frustrations at a later date between groups. For example, in California following the March 11, 2011, tsunami, post-tsunami field teams traveling from outside of the state contacted the state event coordinator and teamed up with state field teams to improve coordination and obtain access to special contacts or locations otherwise off-limits to those personnel (Wilson et al. 2013). The updated UNESCO-IOC post-tsunami fieldsurvey guide (Kong 2011; UNESCO, 2014) provides greater details on plan elements; however, basic elements of a field plan include the following:

- Dates and locations for accommodations and field work;

- Names and affiliations of all pertinent field members;

- Contact information for field team leader and a secondary leader in case the leader cannot be reached;

- Data-collection plan;

- Plan for communicating with state/regional event coordinator;

- Discussion of importance of the collected data to the state/region; and

- Dissemination plan for sharing data with federal, state, regional, and local communities, including dates, data types, and process for sharing. 


\subsubsection{Obtain official survey badge for authorized access}

After receiving approval for survey plans from the designated event coordinator, each researcher would receive official documentation and identification from the coordinator to serve as members of a science-survey team. This approval likely will occur with concurrence from state and federal agencies, and possibly the U.S. National Science Foundation depending on funding sources. Team members will be provided with an official badge that authorizes them to enter the event area. This badge should be visible at all times while in the field and helps public safety and response personnel to identify any individuals that are authorized to be in disaster zones. This is especially important for near-field tsunami disasters, where substantial earthquake aftershocks are possible and structures and infrastructure could fail after being weakened by the initial ground shaking or by tsunami impact. Unauthorized individuals not familiar with their surroundings represent a publicsafety threat to themselves and to the response personnel who may need to rescue them. In addition, unauthorized individuals may not be aware of the sensitive nature of impacts to local communities or special customs of those communities in the aftermath of a disaster. Therefore, researchers without proper credentials issued through the post-tsunami event coordinator would not be allowed into affected areas.

\subsubsection{Include local experts and officials on your field team}

External tsunami researchers on science-survey teams will have considerable knowledge and expertise on tsunami mechanics and how tsunamis impact coastal environments, both from past experiences and theoretical work. In many cases, they will, however, lack preevent knowledge of the impacted area, including its physical layout, development, and culture. This local knowledge may be critical as science-survey teams attempt to decipher what impact tsunamis had in an area. Having some sense of what the area looked like before the tsunami is important if one is to document changes. For example, certain infrastructure or coastal habitats may have already been damaged prior to a catastrophic tsunami and accidentally included in a post-disaster impact assessment. Equally important and often critical for successful surveys will be respect for community organizations or leaders, as well as customs, cultural, or religious practices, and in some locations, knowledge of the local language.

The event coordinator can arrange meetings between local officials and scientists as appropriate. This could be started prior to the beginning of field-data collection to adequately inform officials of what to expect and to solicit information and involvement from local experts. The event coordinator could provide a list of the officials and the local experts to all team members. The extent of this coordination with local experts will vary for each event and for each affected place based on local needs and availability of local experts. For example, local experts may be survivors of the extreme event and dealing with personal and work-related losses. Therefore, researchers should respect the needs and nonwork constraints placed on local experts.

\subsubsection{Coordinate plans and communication procedures with other science-survey teams and with government agencies}

Post-disaster environments are initially chaotic and may continue to be so for weeks to months after an event; therefore, the potential for not acquiring vital information or conducting overlapping and redundant surveying efforts is high. To minimize this potential 
and to maximize the time and resources of all science-survey teams, it is important that teams coordinate all aspects of their activities with the state and/or territorial government and other science-survey teams. In a Presidentially declared disaster in the USA, it would be necessary to coordinate efforts with the federal and state coordinating officers, who are appointed to organize response and recovery efforts, such as through the FEMA-led Joint Field Office (JFO) and Federal Coordinating Officer (FCO). The JFO is established locally to facilitate field activities and provides a central location for coordination of federal, state, local, tribal, non-governmental, and private-sector organizations with primary responsibility for activities associated with threat response and incident support. Survey issues to coordinate may include travel, field logistics, equipment and vehicles, lodging, and meetings with state/territorial/local officials. In addition, response personnel will benefit from receiving updates from field researchers on the status and physical conditions of certain areas.

Depending on the scope of the event, an event coordinator may need to facilitate multiple teams in coordination with the state/territory/local government, as well as identify the team leads that will be responsible for coordinating with other survey teams. Team leads should be culturally aware of the impacted area, the local government, and other science-survey teams, as well as experienced in conducting tsunami science surveys and accustomed to working in disaster areas.

Communication in the field among science-survey teams and governmental organizations is very important and can be completed through several methods. Prior to the survey start, the preferred method is through an in-person meeting. While in the field, communication could be either via phone, radio, or email. Pre-survey agreement on how to document the coordination for reporting or after action reports should also be in place. Text messaging or social-media platforms could be used if there were established protocols. If these social networks were to be used, the event coordinator (in coordination with the state/ territorial/local government) may limit the number of individuals who will be posting to these sites to ensure accurate messaging and communication of information.

Above all, it is paramount that each team ensures the safety of its members by having robust communications equipment that will reach government officials in case of an emergency. The use of handheld radios, if available to be issued to team leads, should be coordinated with the state/territorial or local governments. Satellite phones should also be considered. Prior to entering the field, the communication strategy should be defined in the field plan (Sect. 3.1.2).

\subsection{In-field procedures}

\subsubsection{Check in with event coordinator as you enter the field}

Once teams have authorization, field plans, and a confirmed list of members, they will be ready to travel to impacted areas to collect data. Survey teams should check in with the designated event coordinator to let him or her know that they are entering affected areas. This step is important for both coordination and accountability of all involved. The checkin process provides a readily accessible list of team members, and their expected field locations and dates, for use by emergency-response officials. Situational reports provided by the JFO and/or local officials can be shared with survey teams so they are well prepared.

Each event will be different depending on location and severity, but the event coordinator will establish an appropriate process for team members to check in. Depending on local conditions, the severity of the event, and time demands of the event coordinator, the 
check-in process for survey teams may involve a pre-briefing with local officials via webbased system, emails, text messages, personal contact, or social-media platforms (e.g., Twitter and Facebook).

\subsubsection{Heed all safety regulations}

Prior to survey teams heading to the field, the event coordinator will provide them with safety information related to field conditions. Survey-team members should follow all recommendations to ensure their safety while in the field. Response personnel will already be committed to helping survivors of the initial disaster and do not need the additional burden of new victims because researchers fail to heed safety recommendations. It is also important for researchers to realize that field conditions may change and that new safety requirements may be established. The most common occurrences will be strong earthquake aftershocks that may weaken existing structures, and trigger additional tsunami warnings. An extreme recent example is the 2011 Tohoku earthquake and tsunami disaster that quickly evolved into a nuclear accident with the damage sustained at the Fukushima Daiichi Nuclear Power Plant (Tokyo Electric Power Company 2013). Cascading hazards are possible and researchers should be aware of the interconnectedness of natural and technological hazards across a region.

\subsubsection{Be prepared to answer questions by response personnel, officials, media, and survivors}

Survey team members will bring a wealth of knowledge and expertise to a tsunami disaster zone. Although they may be focused only on their data-collection plans, researchers should be prepared to answer questions from response personnel, officials, the affected community, the media, and the general public. Questions may stem simply from curiosity in fieldwork and how the information gathered will be used. Survivors may also be concerned with the chance of the reoccurrence of events in the short term, and will likely inquire about when and what government assistance to expect. Team members should work with coordinators and be prepared to answer these questions, because silence may be perceived as an intention to hide information from the public, which may then be negatively associated with the state/territorial government. Also, these periods of silence will be filled by less-qualified individuals (e.g., on either broadcast or internet media outlets) if officials or researchers decline to answer the questions. Since the likelihood and magnitude of future events are often difficult to gauge, it is recommended for all survey teams to be provided with a script with basic talking points, information, and points of contact for further information. This could be the responsibility of the event coordinator, who often will be responsible for resolving any questions or concerns about the survey teams raised by response organizations or local officials.

As discussed earlier, response personnel and officials may wish to get updates on conditions in impacted areas. They also may turn to external researchers for advice on relief and recovery operations if a researcher has extensive experience in post-tsunami environments. When answering questions, researchers should be clear on their background and expertise, because local officials will not be able to make these distinctions and may place inappropriate weight to a researcher's perspective. For example, a researcher's opinion on recovery priorities in disaster zones may dominate local decision making, even though he or she is a natural scientist with no expertise in community development or land use planning. Local officials may simply see the advanced degree and professional 
standing and may defer their knowledge and expertise of local values and priorities. All communications between field researchers and the media or public should be shared with the event coordinators to keep all parties adequately informed.

\subsection{Exiting the field}

\subsubsection{Follow check-out procedures and provide out-briefing to response officials}

Upon completion of field-data collection, researchers should follow check-out procedures that have been established by the designated event coordinators in collaboration with state/ territorial/local officials. This should include a summary of accomplished work, as well as a plan and schedule for sharing field data, especially with agencies that have an immediate need. Providing an explicit plan for sharing data will help minimize any unrealistic expectations for those wishing to receive data and helps keep the researcher accountable to the agencies that provided resources to enable the survey team's efforts.

To assist agencies that may have immediate uses for field data, researchers should work with the designated event coordinator to identify which organizations could use field data and what timelines these groups may have. Timelines for impacted local and state government agencies will likely vary from days to weeks for damage and hazard assessments, to several months for non-emergency survey information. Based on past disasters, some researchers have noted that it is often difficult to completely analyze data and report findings due to insufficient funding and time. Researchers may want to build in funding and time in grant proposals for completing post-tsunami field reports. If field reports cannot be provided in a timely manner, then briefings should be scheduled with those with immediate needs so the results can be shared verbally. If feasible, draft maps showing inundation and run-up boundaries could be provided to the response officials to assist in the response and recovery efforts. Arrangements can be made to protect outside data sharing if data provided to the event coordinator has not yet been published or is considered proprietary.

\subsubsection{Provide final data to the appropriate users in a timely fashion}

The final step for field researchers is to ensure that their data end up in an appropriate data repository. This helps ensure that their efforts and observations will be accessible to future researchers and practitioners. This includes individuals in the affected area, since future generations may forget historic events and how their community recovered. This information also serves as a rich database for study and application of findings to areas yet to be impacted by similar events. This is especially important because few coastal communities have recent experiences of catastrophic tsunamis; therefore, a tsunami disaster at one site must be considered a living laboratory of risk-reduction and post-event resilience for all coastal communities. Time and funding should be included in grant proposals to archive field data in a format useful for others.

Archiving final data can take several forms and currently there is not one standard approach. The U.S. National Science Foundation, for example, requires a data archive form with its rapid response grants (National Science Foundation 2013). The NOAA National Geophysical Data Center operates the International Council of Science (ICSU) World Data Service for Geophysics which includes tsunamis. One area for future discussion is the development of a technical clearinghouse on a secure web server that could provide a depository for all data related to the event. 


\section{Next steps}

The proposed PTSS protocol has no regulatory or statutory authority to enforce it. Therefore, the implementation and ultimate success of the protocol are dependent on it gaining widespread support and use by the science and emergency-management communities, as well as organizations that fund field teams. PRiMO and the NTHMP originally sponsored the PTSS protocol and will continue to support its development. Progress and updates will be provided at annual meetings of both organizations and coordinated by the existing working group. Work group representatives will continue to share and describe the protocol to agencies and academic institutions that have responsibilities or interests in posttsunami response and support. It is also being shared with related state/territorial governmental agencies to assure that government officials are aware of the procedures and establish communication procedures within their offices. The PTSS protocol work group is also committed to holding meetings with key federal agencies, institutions, and stakeholders, such as FEMA, NOAA, the USGS, and the U.S. National Science Foundation.

Significant progress has been made in integrating the PTSS protocol into existing program work plans. For example, the NTHMP formally approved the inclusion of the PTSS protocol guidelines in its 2013-2017 Strategic Plan (NTHMP 2013). The strategy sets as a milestone achievement the development of plans for implementing post-tsunami protocols for field teams, and enables NTHMP states, territorial, and commonwealth partners to apply for funding for plan development and assigning of post-tsunami event coordinators. The NTHMP has also funded real-time tsunami impact observer networks in Hawaii and California that will follow the PTSS protocol (Wilson et al. 2013). The NTHMP and PRiMO agreed to continue discussions on the establishment of the posttsunami event coordinator network, which is integral to the success of the protocol. In addition, this tsunami protocol will be included in the U.S. National Plan for Disaster Impact Assessments: Weather and Water Data (Office of the Federal Coordinator for Meteorology 2010) that guides federal agency coordination for any post-tsunami science response in the USA.

Current work of the PTSS workgroup focuses on developing guidelines for a survey website that will assure effective and meaningful communication during a survey, in addition to the feasibility of developing a technical clearinghouse for post-tsunami data storage and retrieval. Opportunities will be sought to test the protocol in conjunction with either federal or state scenario-planning activities. Potential funding sources to support teams that implement the PTSS protocol in the future tsunamis are also being identified.

The aftermath of a catastrophic tsunami will be chaotic but also provides an incredible and ephemeral opportunity for learning more about tsunami dynamics, landscape changes, and response and recovery operations. A protocol for coordinating PTSSs hopefully will minimize the confusion and potential redundancies of post-event surveys, while also maximizing the efficiency and effectiveness of data-collection efforts by leveraging local knowledge and relationships. The PTSS coordination protocol also can serve as the documentation that is required to defend requests for funding from agencies and institutions immediately after a disaster has struck. Timely information gleaned from well-organized science surveys can provide insight to on-site response and recovery operations, tsunami science, and risk-reduction planning elsewhere in the world. Although the coordination protocol was designed from a US perspective, we believe it could support PTSSs in other areas and further the discussion on how researchers can most effectively operate in disaster environments. 
Acknowledgments We thank Mara Tongue and Stephanie Ross of the USGS, John Parrish and Tim McCrink of the California Geological Survey, Lori Dengler of Humboldt State University, and two anonymous reviewers for their insightful reviews of the manuscript. Any use of trade, product, or firm names is for descriptive purposes only and does not imply endorsement by the US Government. This study was partially supported by the USGS Land Change Science Program and the National Tsunami Hazard Mitigation Program.

Open Access This article is distributed under the terms of the Creative Commons Attribution License which permits any use, distribution, and reproduction in any medium, provided the original author(s) and the source are credited.

\section{References}

Borrero J, Titov V, Ortiz M, Synolakis C (1997) Field survey of Mexican tsunami produces new data, unusual photo. Eos, Trans Am Geophys Union 78(8):85-88

Dengler L, Nicolini T, Larkin D, Ozaki V (2008) Building tsunami-resilient communities in Humboldt County, California In Wallendorf L, Ewing L, Jones C, Jaffe B (eds) Solutions to Coastal Disasters 2008-Tsunamis, American Society of Civil Engineers, p 178-191

Kong L (2011) Ocean policy-post-tsunami field surveys are essential for mitigating the next tsunami disaster. Oceanography 24(2):222-226

Kong L, Steffen J, Dominey-Howes D, Biukoto L, Titimaea A, Thaman R, Vaa R (2009) A new approach to UNESCO-IOC Post-tsunami field surveys, session U23F-01: The 29 September 2009 tsunami and earthquake II. EOS Trans AGU

Kong L, Chiesa C, Dunbar P, Huart J, Richards K, Shulters M, Stein A, Tamura G, Wilson R, Young E (2011) Coordination post-tsunami field surveys in the US, session NH25. Great disasters of the XXI Century: the lessons we learned. EOS Trans AGU

National Geophysical Data Center/World Data Service for Geophysics (2013) Global historical tsunami database. DOI:10.7289/V5PN93H7. Available at http://www.ngdc.noaa.gov/hazard/tsu_db.shtml. Accessed 29 Dec 2013

National Science Foundation (2013) Grant proposal guide. Available at http://www.nsf.gov/pubs/ policydocs/pappguide/nsf13001/gpg_2.jsp\#IID1. Accessed 26 Dec 2013

National Tsunami Hazard Mitigation Program (2011) Post-tsunami procedures. Proceeding paper of 2011 NTHMP Annual Meeting, American Samoa, 3 pages

National Tsunami Hazard Mitigation Program (2013) 2013-2017 Strategic Plan, 32 p. Available athttp:// nthmp.tsunami.gov/documents/NTHMPStrategicPlan.pdf. Accessed 26 Dec 2013

Office of the Federal Coordinator for Meteorology (2010) National plan for disaster impact assessmentsweather and water data.United States department of commerce, FCM-P33-2010, Available at http:// www.ofcm.gov/p33-npdia/fcm-p33.htm. Accessed 26 Dec 2013

Pacific Risk Management 'Ohana (2011) Pacific partners meeting report. Available at http://collaborate.csc. noaa.gov/PRiMO/Shared\%20Documents/Forms/meeting.aspx. Accessed 29 Oct 2012

Piatanesi A, Tinti S, Gavagni I (1996) The slip distribution of the 1992 Nicaragua earthquake from tsunami run-up data. Geophys Res Lett 23(1):37-40

Satake K, Bourgeois J, Abe K, Abe K, Tsuji Y, Imamura F, Iio Y, Katao H, Noguera E, Estrada F (1993) Tsunami field survey of the 1992 Nicaragua earthquake. Eos, Trans, Am Geophys Union 74(13): p. $145,156-157$

Sato H, Shimamoto T, Tsutsumi A, Kawamoto E (1995) Onshore tsunami deposits caused by the 1993 Southwest Hokkaido and 1983 Japan Sea earthquakes. Pure appl Geophys 144(3-4):693-717

Synolakis C, Okal E (2005) 1992-2002-Perspective on a decade of post-tsunamisurveys. In: Satake K (ed) Tsunamis-case studies and recent developments, Advances in natural and technological hazards research, 23, Springer, the Netherlands

Synolakis C, Imamura F, Tsuji Y, Matsutomi H, Tinti S, Cook B, Chandra Y, Usman M (1995) Damage, conditions of East Java tsunami of 1994 analyzed. EOS, Trans Am Geophys Union (76): pp. 257, 261-262

Tokyo Electric Power Company (2013) The Great East Japan earthquake and current status of the nuclear power station. Available at http://www.tepco.co.jp/en/nu/fukushima-np/outline/index-e.html. Accessed 26 Dec 2013 
United Nations Educational, Scientific and Cultural Organization (2014) International Tsunami Survey Team (ITST) Post-tsunami survey field guide ( $2^{\text {nd }}$ edition). D. Dominey-Howes and L. Dengler eds, IOC Manuals and Guides No. 37. Paris, UNESCO, p 120

United States Department of Health and Human Services (1979) The Belmont Report- ethical principles and guidelines for the protection of human subjects of research, report of the national commission for the protection of human subjects of biomedical and behavioral research. Available at http://www.hhs.gov/ ohrp/policy/belmont.html. Accessed 24 May 2014

United States Department of Health and Human Services (2014) Federal policy for the protection of human subjects ('Common Rule'). Available at http://www.hhs.gov/ohrp/humansubjects/commonrule/. Accessed 23 May, 2014

Wilson R, Admire A, Borrero J, Dengler L, Legg M, Lynett P, Miller K, Ritchie A, Sterling K, McCrink T, Whitmore P (2013) Observations and impacts from the 2010 Chilean and 2011 Japanese tsunami in California (USA). Pure appl Geophys 170(6-8):1127-1147 